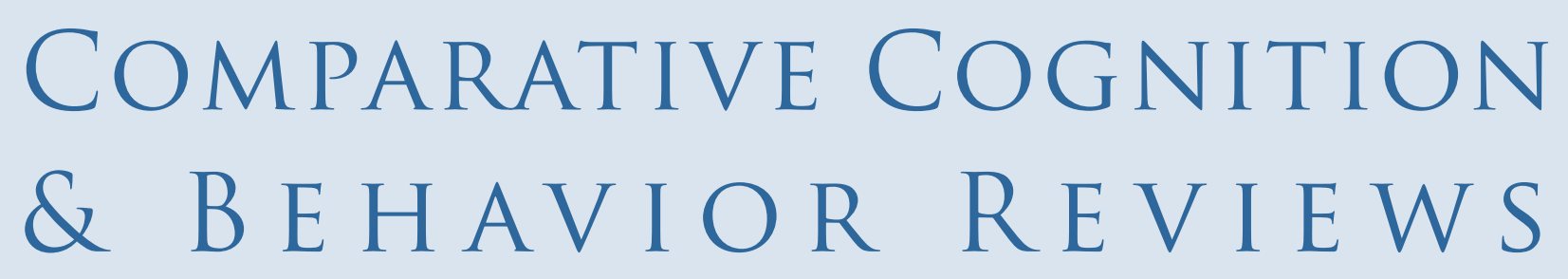

\title{
The Importance of Sensory Perception in an Elephant's Cognitive World
}

\author{
Sarah L. Jacobson and Joshua M. Plotnik \\ Hunter College, City University of New York \\ Graduate Center, City University of New York
}

The three living species of elephants (Elephas maximus, Loxodonta africana, L. cyclotis) have evolved adaptive, sensory perceptual abilities to successfully navigate the physical and social environments in which they live. In this article, we review research evaluating the sensory perception of elephants across four sensory modalities - vision, audition, touch, and chemosensation. We also address how these sensory modalities have been incorporated into empirical investigations of elephant cognition. Last, we discuss the importance of considering sensory perception when interpreting elephants' performance on cognitive tasks and the potential application of perception and cognition research to wild elephant conservation. Our review suggests that elephant cognition experiments should rely less on visual, primate-centric testing paradigms that neglect the elephant's multimodal sensory perception and instead focus on providing elephants with a complete sensory experience. Specifically, where appropriate, elephants should be given access to acoustic and olfactory information in cognitive experiments to ensure that results are due to the elephant's cognitive capabilities rather than confounds of experimental design. Based on what we now know about elephants, attention to their complementary visual, olfactory, and acoustic perception is crucial for understanding how they make decisions in their natural world.

Keywords: sensory perception, elephant intelligence, comparative cognition, vision, audition, touch, chemosensation

\section{Introduction}

The three extant species of the family ElephantidaeAsian (Elephas maximus), African savanna (Loxodonta africana), and African forest (L. cyclotis) elephants - have long trajectories of independent evolution. The African species diverged from the Asian species more than 6 million years ago (Rogaev et al., 2006), and the two African species diverged from each other more than 1.9 million years ago (Rohland et al., 2010). Although these species inhabit somewhat different ecosystems, they are all generalist feeders and consume a wide variety of grasses and browse depending on resource availability (Hatt \& Clauss, 2006). All species are social, with the main social unit centering on adult female relatives and their offspring (Buss \& Smith, 1966; McKay, 1973). The oldest female leads the group consistently in African savanna elephants (Douglas-Hamilton \& Douglas-Hamilton, 
1978), whereas other adult females have been observed leading the group equally as frequently in Asian elephants (Mizuno, Sharma, Idani, \& Sukumar, 2017; Vidya \& Sukumar, 2005). African savanna and Asian elephant females remain in their natal group for their entire lives, cooperating in group defense, care of related offspring, and resource acquisition, whereas males leave the group at sexual maturity (Vidya \& Sukumar, 2005). The family groups have fluid association patterns of fission and fusion that are dependent on seasonality, resource availability, and other social factors (de Silva, Ranjeewa, \& Kryazhimskiy, 2011; Fishlock, Lee, \& Breuer, 2008; Wittemyer, Douglas-Hamilton, \& Getz, 2005). However, African savanna elephants appear to form stronger multilevel, hierarchical societies, whereas African forest and Asian elephants form smaller groups with more loose associations (de Silva \& Wittemyer, 2012). Natal dispersal for both sexes in African forest elephants may also contribute to this difference in social structure (Fishlock et al., 2008). Males in all species experience the phenomenon of musth, a period of heightened sexual and aggressive behavior, increased testosterone levels, and more frequent associations with female groups (Fishlock \& Lee, 2013; Poole, 1987; Rasmussen \& Schulte, 1998). This transient sexual state for males and the infrequent ovulation of female elephants (Moss, 1983) necessitates communicative signals between individuals about sexual receptivity and influences the dynamic nature of the associations between elephants.

An elephant's capacity for perceiving the world has been shaped by the physical and social environmental niches it occupies. This capacity is particularly important for the elephant's navigation of the savanna or the jungle in which it lives, as well as the complex social relationships it has with others. Given the relatively similar social organization (de Silva \& Wittemyer, 2012; Vidya \& Sukumar, 2005) and natural diets (Hatt \& Clauss, 2006; Short, 1981) of the three species of elephant, it is likely that there are considerable similarities in their

Author Note: Joshua Plotnik, Dept of Psychology, 695 Park Avenue (Room 611N), Hunter College, New York, NY 10065

Correspondence concerning this article should be addressed to Joshua Plotnik at joshua.plotnik@gmail.com.

Acknowledgments: We thank two anonymous reviewers, as well as Christopher Braun and Diana Reiss, for constructive comments on earlier versions of this article. S.L.J. is supported by a National Science Foundation Graduate Research Fellowship under Grant No. DGE-1646736. physical and social decision-making. However, because the species have evolved independently for so long in different ecosystems, some perceptual differences may exist. Unfortunately, evaluating behavioral and cognitive differences between the elephant species is difficult given the varying levels of existing research across species. Thus, we distinguish between species when discussing specific studies, but where data are sparse, we generalize to all elephant species. We recognize that although this generalization has been common in elephant research, it may not be accurate for all elephant characteristics, and we hope that future research will help illuminate where such generalizations are not appropriate.

Over the past 70 years, our understanding of elephants' perceptual worlds has improved substantially as we have learned about their sensory anatomy and physiology, tested the bounds of their sensory abilities, and revealed more about the information in the environment that is most important for their survival. Perception of information through various sensory modalities is the input step in the process of cognition for all species (Cahen \& Tacca, 2013). Once sensory information is received, the stimulus is then interpreted based on an individual's experience (their umwelt) and behaviors are produced in response. Therefore, any test of an animal's cognition relies on the animal's sensory perception, regardless of whether that perspective is the focus of study. This means that the umwelt of the species is important to consider when both designing a particular cognitive experiment and interpreting an animal's performance. In this article, we first discuss research that furthers our understanding of the elephant's use of the four main modalities of sensory perception (visual, auditory, tactile, chemosensory) in all species of elephant, as well as the cognitive studies that have relied on the elephant's use of each modality. Then we discuss the importance of understanding elephants' sensory perception when assessing their cognitive abilities and in the development of solutions to problems in elephant conservation.

\section{Vision}

As the largest living land mammals, elephants rarely face the threat of predation. However, some carnivores will prey on infant elephants (Andheria, Karanth, \& Kumar, 2007; Loveridge, Hunt, Murindagomo, \& Macdonald, 2006; Ruggiero, 1991), and humans have become a major predator, as elephants are hunted for their tusks (Wittemyer et al., 2014) and skin (Sampson et al.,

COMPARATIVE COGNITION \& BEHAVIOR REVIEWS 
2018). African savanna elephants have been observed orienting toward and mobbing lions (Douglas-Hamilton, 1972; Moss, 1988), behavior that may indicate that vision is important for locating and tracking predators at close range. However, research on visual predator detection in elephants is lacking, as the only published experimental study of nonhuman predator detection by elephants focuses on audition (Thuppil \& Coss, 2013). In social contexts, vision may be important for monitoring conspecifics for threatening or affiliative signals such as folding and flapping of the ears (Douglas-Hamilton, 1972) or body postures related to the sexual states of estrus (Moss, 1983) and musth (Poole, 1987) that signal fertility or reproductive readiness. Researchers studying African savanna elephants have compiled ethograms of the visual signals that elephants exhibit in different contexts (Kahl \& Armstrong, 2000; Poole \& Granli, 2009), yet research has not been done to confirm how visual signals are interpreted by conspecifics. Behaviors that humans interpret as visual signals may instead be used to enhance other, nonvisual information or be a by-product of nonvisual sensory production. For example, a male elephant may perform a particular ear wave display that researchers have associated with a signal for musth (Poole, 1987). However, conspecifics may not perceive the visual ear wave as a signal for musth; rather, the wave could be wafting the temporal gland excretion into the air and spreading this salient chemical cue for the bull's reproductive state (Langbauer, 2000). Another example could be an elephant's body posture with ears extended that has been interpreted as signaling aggression or dominance (McKay 1973; Poole \& Granli, 2009). Although this posture may function to make an elephant appear larger, it is also possible that extended ears enhance an elephant's ability to receive and localize acoustic signals coming from a conspecific or perceived threat.

Research into the anatomical features of the elephant eye and associated brain areas has informed our understanding of elephant vision, although this research is relatively limited. The visual axis of the elephant eye is directed laterally because of the eyes' position on the side of the head, yet both eyes can also be seen when facing an elephant head-on. This eye placement led Stone and Halasz (1989) to conclude that elephants use a combination of binocular and monocular vision to locate objects. Their trunk operates in the binocular, higher resolution region of their visual field. Within the African savanna elephant retina there is also a unique concentration of cells in the upper temporal retina, which differs from most other mammals that have weaker visual fields in front of their noses. This retinal feature may allow elephants to visually monitor their trunk (Stone \& Halasz, 1989). Because elephants have evolved a highly prehensile nose and must control its muscles to perform important functions such as gathering olfactory information and food, it would be adaptive for their visual system to receive detailed feedback to coordinate with other senses. The visual pigments in the retinas of Asian and African savanna elephants indicate that they have dichromatic color vision, similar to color-blind humans. This color perception is adaptive for an arrhythmic species such as the elephant, which needs to be able to see sufficiently well at night and during the day when they are active (Yokoyama, Takenaka, Agnew, \& Shoshani, 2005). This perception also would be particularly important for elephants living in dense forested areas where light is more limited. However, African savanna and Asian elephant brain anatomy suggests that, in general, vision is not as important as other types of sensory perception, as the occipital lobe is much less developed than the olfactory bulbs and temporal lobes in the elephant brain (Shoshani, Kupsky, \& Marchant, 2006).

The elephant's visual capacity has been tested explicitly in a few studies. Shyan-Norwalt, Peterson, King, Staggs, and Dale (2010) investigated visual acuity thresholds in one female African savanna elephant using a methodology in which she chose between a rewarded (a complete outline of a circle) and an unrewarded stimulus (an outline of a circle with a gap). The female displayed an acuity to discriminate a gap as small as $2.75 \mathrm{~cm}$ in the circle placed $196 \mathrm{~cm}$ away from her eye. Asian elephants seem to do better by discriminating a gap as small as 0.5 $\mathrm{cm}$, although this was measured using different methodology (Bennett, 1987). Asian elephants can learn to visually discriminate between black and white stimuli and stimuli of different sizes, although there was significant variation in performance between individual subjects, some of which may have been age-related (Nissani, Hoefler-Nissani, Lay, \& Htun, 2005). Asian elephants can also distinguish between photographs of familiar and unfamiliar humans (Polla, Grueter, \& Smith, 2018). In a comparison of visual discrimination abilities between African savanna elephants and sea lions, elephants were able to learn to discriminate between various objects, although not as quickly as sea lions (Savage et al., 1994). Vision may be worse in herbivores than in carnivores, as herbivores are less selective foragers and do not need to track their food (Savage et al., 1994). Elephants in particular forage on a wide variety of plant species that are widely available in their environment (Hatt \& Clauss, 
2006), so specialized vision may not be integral to their foraging strategies or survival.

Many empirical investigations of cognition in elephants have involved visual perception, particularly those that have a basis in primate research. Although visual discrimination tests can evaluate the visual perception abilities of individual subjects, studies using these paradigms often also evaluate the animal's capacity for learning and categorization. For example, Bates et al. (2007) found that wild African savanna elephants could discriminate between the garments worn by an ethnic group that had historically threatened the elephants and an ethnic group that had not, revealing that this visual discrimination was used to categorize predation threat. In another visual discrimination task between light and dark stimuli, one Asian elephant demonstrated memory retention of a rewarded stimulus for 8 years (Markowitz, Schmidt, Nadal, \& Squier, 1975). Other researchers have questioned elephants' capacity for learning and cognition based on conclusions drawn from visual discrimination studies (Nissani et al., 2005; Rensch, 1957). Nissani (2006) concluded that Asian elephants lack causal understanding in a task where a lid was visually and physically blocking access to a food reward, as the subjects persisted in touching the lid even when it was not a barrier to the food reward. This result could be attributed to the elephants' prior training rather than a lack of causal understanding in the visual realm. However, in another test of causal understanding that relied on the Asian elephant subjects' visual perception of means-end relationships, one individual consistently chose the tray that was connected to food over a tray missing the causal link (Irie-Sugimoto, Kobayashi, Sato, \& Hasegawa, 2008). Therefore, elephants may have the capacity to understand and assess some causal relationships using vision. One Asian elephant even demonstrated insightful problem-solving by using a plastic cube as a tool to stand on and reach a hanging reward, a solution that probably involved vision among other sensory modalities (Foerder, Galloway, Barthel, Moore, \& Reiss, 2011). Asian elephants' understanding of quantity and numerosity has been assessed primarily in the visual realm (Irie, Hiraiwa-Hasegawa, \& Kutsukake, 2018), although often the task does not preclude the elephant from using other sensory information such as smell or sound, particularly when food is involved (Irie \& Hasegawa, 2012; Irie-Sugimoto, Kobayashi, Sato, \& Hasegawa, 2009).

Visual perception has been key in tasks assessing elephant social cognition. For example, perspective-taking tests involved blocking one of two people's visual perspectives when both people seemed to be holding food rewards and observing which person Asian elephants would approach to beg for food. This test required subjects to perceive that a human's vision was blocked and to take their visual perspective, which subjects were able to do in some conditions of the study (Nissani, 2004). Captive African savanna elephants demonstrated increased motivation to get food out of novel feeding apparatuses after having visual access to a conspecific retrieving food from the same locations, which may be evidence of a capacity for social learning (Greco, Brown, Andrews, Swaisgood, \& Caine, 2013). Social-cue-following performance has been evaluated using pointing and body orientation cues provided by humans in several studies with Asian and African savanna elephants, although results suggest that African savanna elephants may be better at following such cues than Asian elephants (Ketchaisri, Siripunkaw, \& Plotnik, 2019; Plotnik et al., 2013; Smet \& Byrne, 2013). The studies had differences in methodology, but one specieslevel ecological difference that may explain the results involved the environments in which these different species live. Elephants on the savanna may have greater need for a visual capacity that allows them to localize predators or follow cues from conspecifics in wideopen spaces, whereas forest-dwelling elephants may rely more on nonvisual cues when line of sight is obstructed (Ketchaisri et al., 2019). The use of visual information may be especially important when olfactory information is compromised by variable weather patterns such as wind or precipitation (Ruzicka \& Conover, 2012).

Last, mirror self-recognition - a paradigm that assesses an animal's ability to recognize itself in a mirror and is thought to be associated with a capacity for self-awareness and empathy - relies mainly on an animal's ability to learn about the visual contingencies of a mirrored surface and reflective image (see Figure 1; Gallup, 1970, 1982; Plotnik, de Waal, \& Reiss, 2006). Passing the typical mirror self-recognition test also requires attention to visual appearance and a visible mark that is applied to the animal's body. The significance of a visual mark appears to differ between primates and nonprimates (Marino, Reiss, \& Gallup, 1994) and may explain differences in results between species that maintain their bodies by either taking debris off or putting it on themselves. For instance, elephants - an animal that typically coats itself in mud and dirt as a layer of protection from the sun and insects - may not find a visual mark on its body as significant as an animal that regularly grooms (e.g., corvids: Prior, Schwarz, \& Güntürkün,

COMPARATIVE COGNITION \& BEHAVIOR REVIEWS 
2008; chimpanzees: Gallup, 1970). Variability in success among Asian elephants for mirror self-recognition may be due to differences in methodology; particularly, when elephants had complete access to the mirror, they would likely be able to use a complement of visual, tactile, and olfactory cues to investigate the mirror surface (Plotnik et al., 2006; Povinelli, 1989). Ultimately, our understanding of elephant vision suggests that their vision may be most relevant to them in a social context, where attention to the visual behavioral signals of conspecifics involves a multimodal perspective.

\section{Audition}

Elephants live in closely knit social groups, and auditory communication between individuals allows for maintenance of social bonds, coordination of actions, and responses to potential threats. When an elephant in a social group exhibits distress, others often vocalize toward the distressed individual as a signal that may function as reassurance (Moss, Croze, \& Lee, 2011; Plotnik et al., 2014). Affiliated social groups rely on vocalizations to find each other, and some groups may use these signals to avoid unfamiliar individuals (Fishlock \& Lee, 2013; McComb, Moss, Sayialel, \& Baker, 2000). After sexually mature male elephants disperse from family groups, their movement patterns, especially in relation to social contact, are often motivated by the presence of unrelated estrus females (Poole, 1987). Brief and infrequent female ovulation requires communication about fertility and reproductive receptibility across variable distances between males and females (Moss, 1983)

Figure 1. An Asian elephant investigates a mirror. (Image credit: Joshua Plotnik)

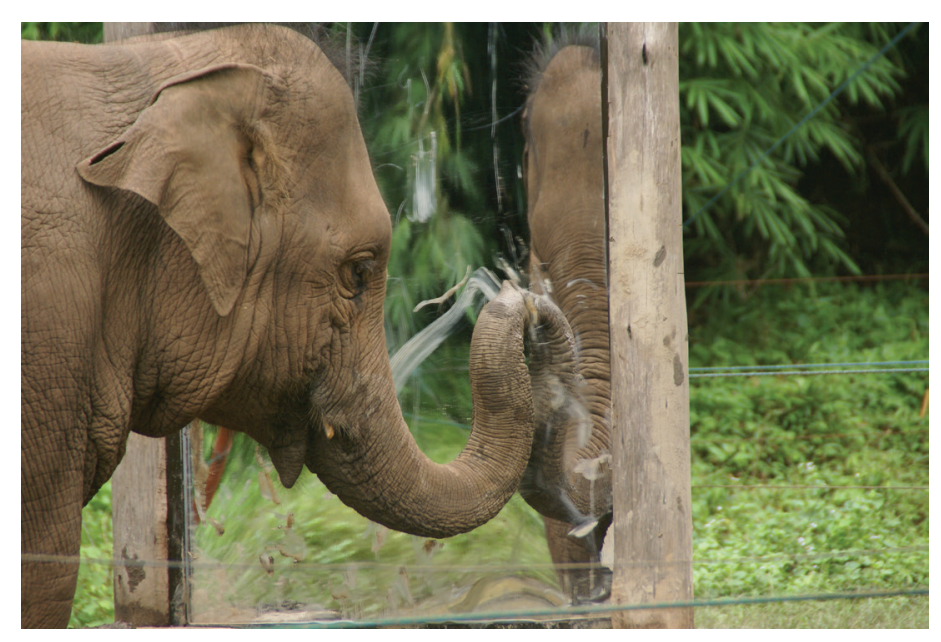

and between males in competition for females (Poole, 1987). Vocal communication appears to be integral to this coordination, including distinct estrous and musth rumbles during these sexual states (Poole, Payne, Langbauer, \& Moss, 1988). A wide variety of vocal signals for short- and long-distance communication have been documented in all of the elephant species, ranging from the higher frequency screams, trumpets, and roars to lower frequency rumbles or growls (reviewed by Langbauer, 2000). Much of the research on elephant communication has focused on the production of different vocalizations and their potential functions (e.g., Berg, 1983; Soltis, Leong, \& Savage, 2005a) rather than on how these auditory signals are perceived.

Audition is an important sensory mechanism allowing conspecifics to perceive and respond to vocal communicative signals, especially when elephants are separated by long distances. Behavioral responses of elephants to vocalizations have been used as evidence for their signal perception, such as when they extend their ears in a rigid position to listen (Poole, 1999), respond vocally to calls from other individuals (Soltis, Leong, \& Savage, 2005b), or approach playback speakers (Poole, 1999). Martin (1978) observed African savanna elephants coordinating movements across long distances, over which olfactory communication would be unlikely. This supports the idea that an alternative sensory mechanism may have been involved in this coordination. Payne, Langbauer, and Thomas (1986) found that Asian elephants are capable of communicating infrasonically at a frequency below human hearing, and further investigations suggest that African savanna elephants in particular listen for and respond to either audible (to humans) or infrasonic contact calls over a range of short and long distances (Poole et al., 1988). These infrasonic calls have also been recorded in African forest elephants and are even used as a method of population estimation (Thompson, Schwager, \& Payne, 2010).

Long-distance communication also allows for warnings of potential danger to be transmitted between social groups. This has been observed in field experiments where African savanna elephant groups form dense aggregations to protect calves in response to distant conspecific alarm calls (O'Connell-Rodwell et al., 2006). Even though, as previously mentioned, elephants do not have many predators, they do appear to perceive and react to specific sounds of potential threats such as human vocalizations (McComb, Shannon, Sayialel, \& Moss, 2014), leopard and tiger growls (Thuppil \& Coss, 2013), and the buzzing of bees (bees can sting them on sensitive parts of 
their skin - King, Douglas-Hamilton, \& Vollrath, 2007; King et al., 2018). Perceiving these auditory signals may be especially important for elephants in a forested environment where they cannot visually perceive a potential threat or when the threat can be perceived earlier using audition. To test this idea, future experiments should compare the three elephant species' behavioral responses to playbacks of predators or conspecific alarm calls in their respective environments.

The size of an animal's auditory organs relates to its capacity for perceiving sound, particularly in terms of the response of the ear to received frequencies (von Békésy \& Wever, 1960). As a large mammal, the elephant has large auditory organs, specifically the pinnae of the ear and the middle ear structures (the tympanic membrane, malleus, incus, and stapes). The large mobile pinnae help elephants to localize sounds in their environment (Heffner, Heffner, \& Stichman, 1981). The distance between the ears (or size of the head) has also been observed to be inversely related to an animal's ability to hear high-frequency sounds. Thus, an elephant's large head may limit its ability to hear high frequencies, and the large auditory organs may lead to a greater ability to perceive low-frequency sounds (Heffner \& Heffner, 1981). Enlarged nuclei discovered in African savanna elephant brain stems are also likely to play a role in the reception and interpretation of these infrasonic vocalizations (Maseko, Patzke, Fuxe, \& Manger, 2013). The perception of low-frequency infrasonic sound waves that travel through the air seem to be particularly important to elephants, as vocalizations in this range represent a large subset of an elephant's vocal repertoire (Payne et al., 1986).

When the low-frequency vocalizations produced by elephants travel through the ground, they can be transmitted as seismic Rayleigh waves. One way that these seismic vocalizations may be perceived is through bone conduction of the sound into the ossicles of the ear. With this pathway, vibrations transmit from the ground through the bones of the legs to the middle ear cavity, where they then reach the ossicles, and sound waves are transmitted to the brain (O'Connell-Rodwell, 2007). Maseko et al. (2013) identified enlarged nuclei in the African savanna elephant thalamus that appear to be related to the perception of these seismic signals. The behaviors observed in elephants such as freezing and leaning forward on their front feet when receiving seismic information suggest that they are perceiving some of these sounds through bone conduction. Fat in the elephant foot may enhance acoustic conduction for more efficient perception of these seismic cues as well (O'Connell-Rodwell, 2007).

Elephants' auditory abilities were initially investigated by testing the limits of their auditory perception. One Asian elephant, for instance, did not perceive sounds above $12,000 \mathrm{~Hz}$, whereas humans can hear up to $19,000 \mathrm{~Hz}$ (R. S. Heffner \& Heffner, 1982). However, this same elephant was able to hear sounds as low as $17 \mathrm{~Hz}$, below the human range of hearing $(29 \mathrm{~Hz})$. In another experiment, this elephant was able to localize sounds within an angle of $1^{\circ}$ (Heffner \& Heffner, 1982). In more recent research on the perception of sound over distances using playback calls from individuals within a family group, African savanna elephants reacted to familiar calls as far as $2.5 \mathrm{~km}$ away from the source (McComb, Reby, Baker, Moss, \& Sayialel, 2003). Because many environmental factors may affect the transmission and quality of a signal before it reaches the receiver, acoustic behavioral tests may ultimately present problems for assessing the sensitivity of an elephant to the quality and distance of sound (Garstang, 2004). Elephants have also been tested on more fine-scale, ecologically valid discriminations. African savanna elephants are able to discriminate contact calls from an average of 14 families, which include vocalizations of 100 individuals (McComb et al., 2000). Discriminations of familiar versus unfamiliar infrasonic (Stoeger \& Baotic, 2017) and seismic (O'Connell-Rodwell et al., 2007) calls by males and females have also been demonstrated in wild African savanna elephants. In a playback experiment of male musth and female estrus vocalizations, African savanna elephants showed distinct responses that were dependent on their own sexual state, demonstrating their capacity for discriminating between these signals (Poole, 1999).

Cognitive tests requiring the elephant's use of audition are rarer than those requiring vision. Even if audition is not the main mode of testing, auditory signals can be integral in training different testing paradigms. This is especially true for captive elephants, when communication between the researcher or caretaker and the subjects is crucial for the paradigm (e.g., Plotnik et al., 2013; Smet \& Byrne, 2013). One Asian elephant even demonstrated an ability to perceive distinct formants and the fundamental frequency of Korean speech well enough to then imitate human caretakers (Stoeger et al., 2012). In one of the earliest studies of elephant cognition, Rensch's (1957) single Asian elephant subject learned to discriminate between six pairs of tones and associate tones with positive or negative outcomes, demonstrating

COMPARATIVE COGNITION \& BEHAVIOR REVIEWS 
the elephant's use of acoustic information in memory and categorization. Rensch also described melody recognition in this elephant even when the melody's frequency, intensity, rhythm, and timbre were changed. In some of the aforementioned studies of individual recognition of communication signals in African savanna elephants, the research addressed not only auditory perception but also aspects of elephant cognition such as categorization and memory (McComb et al., 2000, 2003). For example, McComb et al. (2014) found that savanna elephants behaved differently based on the perceived threat associated with the acoustic signals of particular categories of humans. Auditory information was also provided in a cognitive foraging paradigm where one of two shaken buckets contained sunflower seeds, but the Asian elephant subjects were not able to locate food using this information (Plotnik et al., 2014). Although the elephants likely could have learned this association over time, the researchers were focused on determining which sensory modality was most important within the foraging domain. When considering the ecology of the elephant, it makes sense that they would not be sensitive to the auditory cues of their typically "silent" plantbased food sources (Plotnik et al., 2014). Overall, this research suggests that the use of acoustic sensory information, as with vision, is most relevant for an elephant within its social cognitive world.

\section{Touch}

Tactile perception generally appears to be important for social communication in all elephant species across short and long distances. Direct touching between elephants can signal important information about either affiliative or agonistic interactions, with the trunk most commonly used to initiate tactile behavior, although the head, tail, and entire body can also be used (see Figure 2; Makecha, Fad, Kuczaj, 2012). Elephants often greet each other by entwining trunks and touching their trunks to different parts of each other's bodies. Those with close social relationships will also stand with their bodies touching, particularly mothers and calves (Moss, et al., 2011). Elephants can engage in trunk wrestling, tusk sparring, and pushing as agonistic interactions as well (Langbauer, 2000). Adults will discipline calves using different tactile interactions such as slapping with the trunk, kicking, or shoving (Lee \& Moss, 1986). Physical contact has also been observed as a reassurance response between Asian elephants in a social group following a distressing event (Plotnik \& de Waal, 2014) and is common between mothers and calves (Gadgil \& Nair, 1984; Moss et al., 2011). In general, tactile interactions that involve the trunk may also be linked to chemosensory perception (see the Chemosensation section), and it is impossible to know whether the primary information that the elephants perceive is tactile or chemosensory. However, contact initiated between other parts of the body (the tail, head, or side) is more likely to be perceived as primarily tactile information.

Tactile interactions are perceived by the mechanoreceptors on the skin of the elephant, which vary in sensitivity across parts of their body (Mikota, 2006). The elephants' trunk tip perceives fine tactile interactions, as the skin of the trunk is particularly sensitive and highly enervated with three types of sensory receptors. Beyond social interactions, this level of tactile perception may contribute to their ability to manipulate small objects or food sources using their trunk (see Figure 3; Rasmussen $\&$ Munger, 1996). For instance, one study demonstrated that an elephant can perceive differences as small as $0.25 \mathrm{~mm}$ in the grooves of textured objects (Dehnhardt, Friese, \& Sachser, 1997).

Tactile perception may also contribute to seismic communication between elephants across long distances. Another proposed pathway for perception of these vocalizations that travel through the ground, other than the bone conduction mentioned earlier, is somatosensory perception of the seismic vibrations through elephants' feet (O'Connell-Rodwell, 2007). Elephants have similar mechanoreceptors in their trunk and in the front and back of each foot (Bouley, Alarcón, Hildebrandt,

Figure 2. Mutual touching between an African elephant and a calf. (Image credit: Sarah Jacobson)

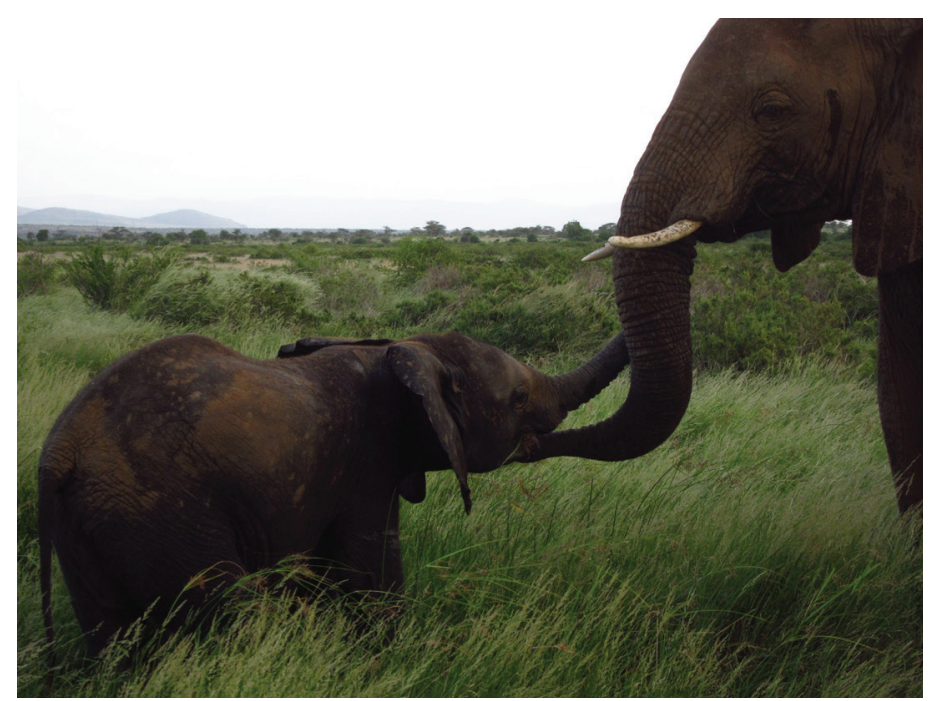




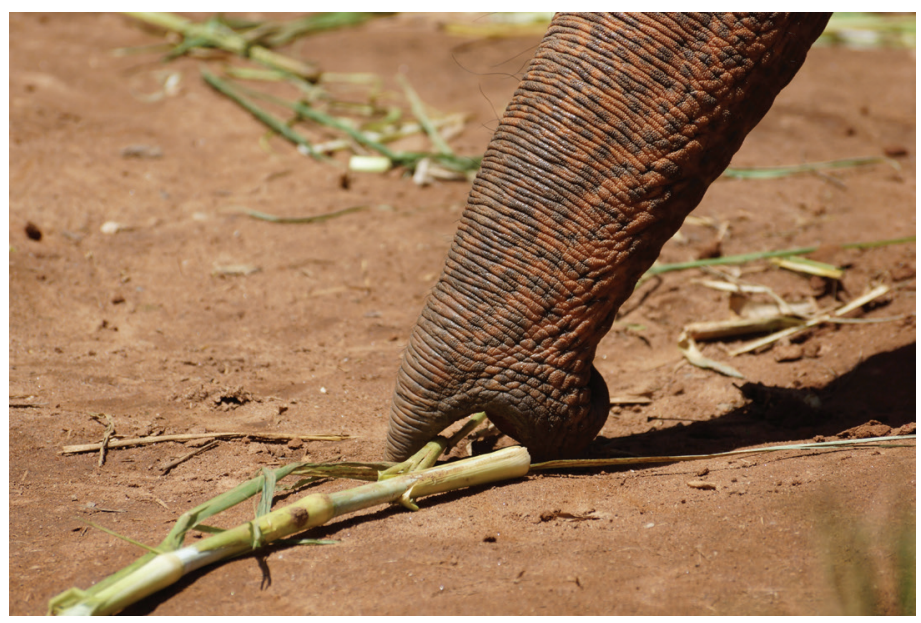

Figure 3. An Asian elephant uses her trunk to investigate food on the ground. (Image credit: Think Elephants International)

\& O'Connell-Rodwell, 2007). When elephants receive seismic communication, their behavioral response of leaning forward on their toes or back on their heels also supports this theory. Perceiving seismic communication using the vibration receptors of the feet may also provide an advantage over airborne perception for localizing the source of these signals, as the long wavelengths would be harder to localize using the relatively short distance between the ears (O'Connell-Rodwell, 2007).

Tests of cognition rarely manipulate tactile information, although it is inherently relevant to tasks involving manipulation with the elephant's trunk. Ethological studies have assessed potential functions of tactile interactions. One study assessing the social cognition of Asian elephants and their responses to conspecifics in distress determined that directed, tactile interactions were greater after distress than during control periods (Plotnik \& de Waal, 2014). Yasui and Idani (2017) further investigated the types of tactile interactions between elephants in different contexts and found that Asian elephants formed two shapes with their trunk for lip and genital touches - an S shape and a U shape. The $\mathrm{U}$ shape was used more frequently during excitement in the social group, sometimes following disturbance, and the $\mathrm{S}$ shape was used more frequently in dominance or aggressive interactions. Potentially, these trunk shapes could reflect an intermediate between a visual and tactile signal (Yasui \& Idani, 2017). Although limited, research on tactile perception in observations of elephant behavior supports the importance of touch for navigating social relationships in elephant groups. The only experimental research that has intentionally incorporated tactile information is a study of body self-awareness in
Asian elephants that assessed the subjects' perception of their own body in space relative to objects around them. In this experiment, the elephants demonstrated an ability to recognize when their own body, which obstructed the movement of a mat on which they stood, was an obstacle to completing a task (Dale \& Plotnik, 2017). Tactile investigation of a mirrored surface also appears to be important for Asian elephants in mirror self-recognition tests, demonstrating the potential relevance of touch to the understanding of the relationship between self, other, and the physical environment (see Figure 1; Plotnik et al., 2006). The use of tactile information by elephants may thus be important both in terms of social communication and in the elephant's physical locomotion within its environment. Clearly, more research within the tactile sensory domain and its interaction with other modalities is needed.

\section{Chemosensation}

The perception of chemicals in the environment through olfaction and detection using the specialized vomeronasal organ allows elephants to gather a wide range of information. Much research has focused on elephants' communication of reproductive states between conspecifics. Female elephants produce a preovulatory chemical signal allowing males to track concentrations signaling their infrequent ovulation (Lazar, Greenwood, Rasmussen, \& Prestwich, 2002). Males also produce chemical cues specific to their sexually active state of musth that elicit different responses from females depending on their estrous cycles (Rasmussen $\&$ Wittemyer, 2002). These cues are adaptive because they can be longer lasting signals of sexual status than visual or auditory signals and can be perceived by individuals that are not continuously in contact with each other. Even dominant social status may be communicated chemically through temporal secretions from musth males.

Rasmussen, Riddle, \& Krishnamurthy (2002) demonstrated that younger, and therefore less dominant, Asian male elephants avoided mature males' musth secretions, whereas older, dominant males did not react to the secretions of younger males. Perception of musth signals helps control competition between males so that they can avoid potentially costly fights (Hollister-Smith, Alberts, \& Rasmussen, 2008). Predators may also be perceived by their chemical signature, although this has been studied only regarding African savanna elephants' recognition of the scents of humans who have historically come into 
conflict with them (Bates et al., 2007). Food resources are also thought to be primarily detected by elephants through olfaction (Plotnik et al., 2014). The chemical cues associated with food content and quality could provide elephants with important information about which resources to pursue when making foraging decisions across long distances.

The anatomy of the elephant olfactory system provides support for the importance of smell to its ecology and behavior. African savanna elephants have more genes for olfaction than any other mammal (Niimura, Matsui, \& Touhara, 2014), and a study of both Asian and African savanna elephant brains revealed that a greater volume is dedicated to olfaction than the other senses (Shoshani et al., 2006). Elephant trunks are also specialized for receiving volatile chemicals. As air is inhaled up the trunk, it is warmed, providing maximum volatility for the inhaled odor as it reaches the high concentrations of olfactory receptors at the base of the trunk (Rasmussen, 2006). The elephant trunk is flexible enough to bend or "periscope" up into the air to collect this olfactory information and determine the direction of the source (see Figure 4). To perceive less volatile chemicals, elephants also have a specialized chemosensory organ called the vomeronasal organ located at the top of their oral cavity (Rasmussen, Lazar, \& Greenwood, 2003). This chemoreceptive organ is present in many terrestrial vertebrates and functions to perceive chemicals that are nonvolatile and often contain proteins (Halpern, 1987). Elephants use their trunk to transport the chemicals from urine, temporal glands, and interdigital glands to this organ for detection (Rasmussen et al., 2003).

Researchers are beginning to learn more about elephants' chemosensory abilities experimentally, especially in relation to the detection of food resources. In a two-object choice task, Asian elephants chose a bucket that contained food over an empty bucket when provided with only olfactory cues (Plotnik et al., 2014). African savanna elephants are able to choose their preferred food using olfactory cues, even when their preferred food is masked by the strong scent of another food resource (McArthur, Finnerty, Schmitt, Shuttleworth, $\&$ Shrader, 2019). When trained to choose a particular odorant, Asian elephants were able to discriminate between structurally related odors that differed only by carbon chain length, with comparable performance to mice (Rizvanovic, Amundin, \& Laska, 2013). African savanna elephants have also been trained to detect trinitrotoluene (TNT), and their sensitivity of detection surpassed that of dogs that were similarly trained
(Miller et al., 2015). Schmitt, Shuttleworth, Ward, and Shrader's (2018) research using a Y-maze demonstrated that African savanna elephants can perceive olfactory cues from food sources and make decisions about what food to choose at a distance of $7 \mathrm{~m}$ from the source. The authors suggest that with a larger food patch, detection would likely occur at much greater distances.

Olfaction has been directly involved in the assessment of a few different cognitive abilities in elephants. In a study of Asian elephants' capacity for discriminating quantity using olfaction alone, elephants were able to distinguish between small differences in quantities of sunflower seeds (Plotnik et al., 2019). This result suggests that olfaction may be important for foraging decisions about where to find high quality or large quantities of food. African savanna elephants' perception of chemical cues from urine has been used to study elephant memory, with particular attention to how they use such information to recognize familiar individuals and to remember their locations when out of sight (Bates et al., 2008). Memory for manufactured odorants was also tested in captive Asian elephants, and the subjects were able to maintain their memory for the correct odor stimulus for 16 weeks after training (Arvidsson, Amundin, \& Laska, 2012). Cognitive categorization has been evaluated using the olfactory modality as well. African savanna elephants were able to categorize humans into predators and nonpredators using the scents of two ethnic groups with differing historical interactions with the elephants (Bates et al., 2007). Further, captive African savanna elephants showed high performance when choosing an individual human's scent to match the scent they were given as a sample (von Dürckheim et al., 2018). Olfaction, therefore, may be the sensory modality most relevant to elephants across both physical and

Figure 4. An Asian elephant "periscopes" to investigate the photographer. (Image credit: Think Elephants International)

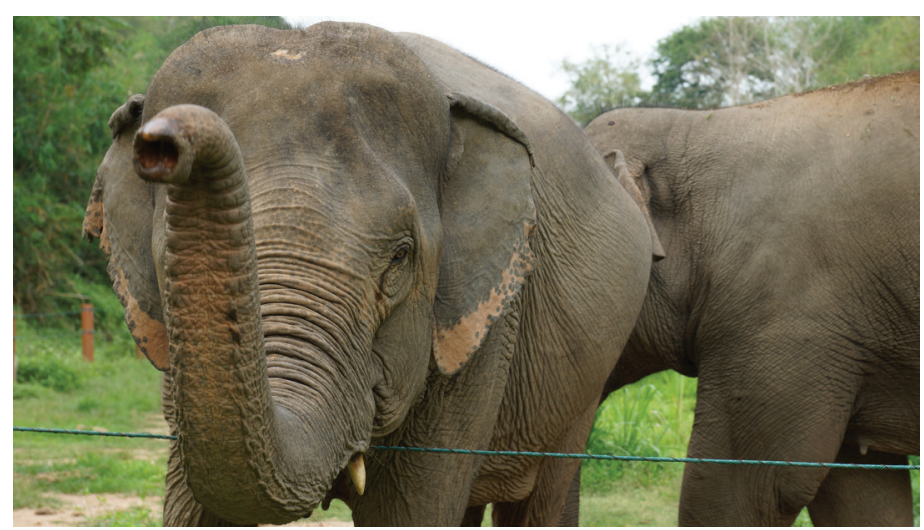


social decision-making, but like all the other senses, elephants may regularly use multiple sensory modalities to perceive their environment.

\section{Discussion}

Much needs to be done to better understand the use of multimodal signaling and perception in elephant cognition. Different signals may be prioritized over others or weighed differently in the process of decisionmaking (Talsma, Senkowski, Soto-Faraco, \& Woldorff, 2010), and it is likely that there is a process of integration in elephants' use of multimodal sensory information, particularly in the social decision-making process. Because of the variance across taxa in perceptual abilities and attention to different senses, it is critically important to understand how species prioritize such information in the cognitive decision-making process. This is particularly relevant in the design of cognitive experiments. It is also important to understand the role that perception plays in different aspects of cognition, as there may be a bias for particular sensory modalities based on the context of a cognitive challenge. For example, elephants could pay more attention to auditory perception in a social rather than a foraging evaluation based on the complexity of the vocal communication signals they can perceive (Langbauer, 2000). However, given the experimental and anatomical evidence for elephants' strengths in chemosensory perception, it is likely most ecologically valid to ask cognitive questions with recognition of this modality (Mumby \& Plotnik, 2018).

In the field of comparative cognition, tests often compare performance by species with an inherent sensory bias toward one over another. This means that mixed results across species on a task may be due to differences in sensory perception rather than cognitive ability. For example, comparing elephants, dogs, and nonhuman primates on a problem-solving task requiring visual attention to cues may be biased toward the visual primates, whereas a foraging task requiring olfaction may be biased toward the nonprimate species. Therefore, when drawing cognitive comparisons between species, it is particularly important to consider perceptual biases in experimental design and to qualify conclusions with information about sensory perception. Furthermore, recognizing our own primate-centric visual bias as researchers and then developing experiments using other sensory modalities is a challenge we must face. This may mean that effective comparisons of cognition should not employ the same paradigms across species but instead use variations on accepted protocols that account for a particular species' sensory strengths.

Beyond the study of cognition, information on elephants' sensory perception could be integrated into conservation strategies. Accepting that decisions about food resources are likely based on olfaction for elephants (Plotnik et al., 2014; Schmitt et al., 2018) may help wildlife managers who want to discourage elephants' use of a particular resource in their ecosystem (i.e. agricultural products) to develop a deterrent in the same modality. For example, understanding the importance of olfaction to elephants may contribute to the development of novel human-elephant conflict mitigation strategies that rely on olfactory deterrents (e.g., chili substances; Chelliah et al., 2010; Hedges \& Gunaryadi, 2010). Knowledge about elephants' perception of acoustic signals could be coopted as a management technique as well, where the use of acoustic playbacks of social signals (i.e., Wijayagunawardane et al., 2016) or the introduction of previously experienced negative stimuli (e.g., the sounds of stinging bees from honeybee fences - King et al., 2018) could be employed to deter or manipulate elephants' approaches to particular locations. Recognizing the unique sensory perspectives of both parties in human-elephant conflict mitigation is crucial for the development of long-term solutions (Mumby \& Plotnik, 2018). Deterring elephants from human areas is a key goal of conservationists trying to reduce the often-negative interactions between humans and elephants that can lead to injury or death. In human-elephant conflict mitigation, it would also be prudent to conduct more research about how elephants may perceive different mitigation methods such as electric fences, loud noises, or bright lights so that the effectiveness of these methods can be evaluated specifically from the elephant's, rather than the human's, sensory perspective.

Trying to apply our understanding of elephant cognition to human-wildlife conflict mitigation is an important focus of our own work, but much of the basic science of elephant sensory perception and cognition has yet to be done. Our current research thus has two primary focuses. The first focus aims to better understand how elephants make decisions within their physical and social environments. For instance, by conducting controlled experiments designed to assess how captive elephants use olfactory information to forage or problem-solve (e.g., Plotnik et al., 2014, 2019), we hope to develop research paradigms for elephants that allow us to draw appropriate comparisons about the evolution of

COMPARATIVE COGNITION \& BEHAVIOR REVIEWS 
cognition across evolutionarily distant species (including primates, birds, and cetaceans). Our own studies on elephant problem-solving, foraging behavior, cooperation, and social learning, for instance, have benefited from an approach that takes the elephant's sensory perspective into account. The second aim of our current research program focuses on applications of wild elephant behavior and cognition to human-wildlife conflict mitigation (Mumby \& Plotnik, 2018). Working in Thailand, we are collecting data on wild elephant behavior in general, with a particular focus on identifying individual differences in behavior and cognition using both ethological and experimental techniques. In the long term, we are hopeful that understanding how individual elephants and their family groups make decisions about where to go for food (e.g., protected, wild habitat vs. nutrient rich, human-guarded crop fields) and how they find that food (e.g., using smell) will help inform conservation in practice. Human-elephant conflict mitigation largely focuses on the needs of humans and the human perspective, with most attempts at solving conflict aimed at physically separating elephants from human habitat. However, these solutions often fail because the elephant's perspective is misunderstood or neglected. Without identifying why and how elephants make decisions that result in conflic, long-term conservation strategies remain incomplete. We hope our work can have a positive impact on wild elephants by contributing to a human-elephant conflict mitigation approach that aims to recognize the importance of understanding both elephant and human needs and behavior in the development of long-term, sustainable conservation strategies.

Research over the past 70 years on the three species of living elephants has shed light on the visual, auditory, tactile, and chemosensory information that elephants perceive in their environment. Although we have presented an overview of what science knows about elephant sensory perception, there are considerable voids in our knowledge across modalities. Due to this need for more research on elephant behavior and perception, it is difficult to draw strong comparisons between the three elephant species, and we have refrained from doing so here. Nonetheless, the strengths, weaknesses, and contexts of different modes of sensory perception must be integrated into investigations of elephant behavior to provide a more holistic perspective of the elephant's cognitive world. Furthermore, perception should be a key consideration in the interpretation of performance on cognitive tests when comparing species. Last, the integration of knowledge about an elephant's sensory world into future strategies for elephant conservation may lead to more effective solutions for this endangered animal's survival in the wild.

\section{References}

Andheria, A. P., Karanth, K. U., \& Kumar, N. S. (2007). Diet and prey profiles of three sympatric large carnivores in Bandipur Tiger Reserve, India. Journal of Zoology, 273(2), 169-175. doi:10.1111/j.1469-7998.2007.00310.x

Arvidsson, J., Amundin, M., \& Laska, M. (2012). Successful acquisition of an olfactory discrimination test by Asian elephants, Elephas maximus. Physiology \& Behavior, 105(3), 809-814. doi:10.1016/j.physbeh.2011.08.021

Bates, L. A., Sayialel, K. N., Njiraini, N. W., Moss, C. J., Poole, J. H., \& Byrne, R. W. (2007). Elephants classify human ethnic groups by odor and garment color. Current Biology, 17(22), 1938-1942. doi:10.1016/j.cub.2007.09.060

Bates, L. A., Sayialel, K. N., Njiraini, N. W., Poole, J. H., Moss, C. J., \& Byrne, R. W. (2008). African elephants have expectations about the locations of out-of-sight family members. Biology Letters, 4(1), 34-36. doi:10.1098/rsbl.2007.0529

Bennett, C. (1987). Visual discrimination and visual acuity in the Asian elephant. In Proceedings of the 8th Annual Elephant Managers Workshop (Vol. 5461), 54-61.

Berg, J. K. (1983). Vocalizations and associated behaviors of the African elephant (Loxodonta africana) in captivity. Zeitschrift Für Tierpsychologie, 63(1), 63-79. doi:10.1111/j.1439-0310.1983.tb00741.x

Bouley, D. M., Alarcón, C. N., Hildebrandt, T., \& O'Connell-Rodwell, C. E. (2007). The distribution, density and three-dimensional histomorphology of Pacinian corpuscles in the foot of the Asian elephant (Elephas maximus) and their potential role in seismic communication. Journal of Anatomy, 211(4), 428-435. doi:10.1111/j.1469-7580.2007.00792.x 
Buss, I. O., \& Smith, N. S. (1966). Observations on reproduction and breeding behavior of the African elephant. The Journal of Wildlife Management, 30(2), 375-388. doi:10.2307/3797826

Cahen, A., \& Tacca, M. C. (2013). Linking perception and cognition. Frontiers in Psychology, 4, Article 144. doi:10.3389/fpsyg.2013.00144

Chelliah, K., Kannan, G., Kundu, S., Abilash, N., Madhusudan, A., Baskaran, N., \& Sukumar, R. (2010). Testing the efficacy of a chilli-tobacco rope fence as a deterrent against crop-raiding elephants. Current Science, 99(9), 419-423.

Dale, R., \& Plotnik, J. M. (2017). Elephants know when their bodies are obstacles to success in a novel transfer task. Scientific Reports, 7, Article 46309. doi:10.1038/srep46309

Dehnhardt, G., Friese, C., \& Sachser, N. (1997). Sensitivity of the trunk of Asian elephants for texture differences of actively touched objects. Zeitschrift fur Saugetierkunde, 62, 37-39.

de Silva, S., Ranjeewa, A. D., \& Kryazhimskiy, S. (2011). The dynamics of social networks among female Asian elephants. BMC Ecology, 11(1), Article 17. doi:10.1186/1472-6785-11-17

de Silva, S., \& Wittemyer, G. (2012). A comparison of social organization in Asian elephants and African savannah elephants. International Journal of Primatology, 33(5), 1125-1141. doi:10.1007/s10764-011-9564-1

Douglas-Hamilton, I. (1972). On the ecology and behaviour of the African elephant (Doctoral dissertation). University of Oxford, Oxford, England.

Douglas-Hamilton, I., \& Douglas-Hamilton, O. (1978). Among the elephants. New York, NY: Penguin.

Fishlock, V., \& Lee, P. C. (2013). Forest elephants: Fission-fusion and social arenas. Animal Behaviour, 85(2), 357-363. doi:10.1016/j.anbehav.2012.11.004

Fishlock, V., Lee, P. C., \& Breuer, T. (2008). Quantifying forest elephant social structure in Central African bai environments. Pachyderm, 44, 19-28.
Foerder, P., Galloway, M., Barthel, T., Moore III, D. E., \& Reiss, D. (2011). Insightful problem solving in an Asian elephant. PLOS One, 6(8), e23251. doi:10.1371/journal.pone.0023251

Gadgil, M., \& Nair, P. V. (1984). Observations on the social behaviour of free ranging groups of tame Asiatic elephant (Elephas maximus Linn). Proceedings: Animal Sciences, 93(3), 225-233. doi:10.1007/BF03186282

Gallup, G. G. (1970). Chimpanzees: Selfrecognition. Science, 167(3914), 86-87. doi:10.1126/science.167.3914.86

Gallup, G. G., Jr. (1982). Self-awareness and the emergence of mind in primates. American Journal of Primatology, 2(3), 237-248. doi:10.1002/ajp.1350020302

Garstang, M. (2004). Long-distance, low-frequency elephant communication. Journal of Comparative Physiology A, 190(10), 791-805. doi:10.1007/s00359-004-0553-0

Greco, B. J., Brown, T. K., Andrews, J. R. M., Swaisgood, R. R., \& Caine, N. G. (2013). Social learning in captive African elephants (Loxodonta africana). Animal Cognition, 16(3), 459-469. doi:10.1007/s10071-012-0586-7

Halpern, M. (1987). The organization and function of the vomeronasal system. Annual Review of Neuroscience, 10(1), 325-362. doi:10.1146/annurev.ne.10.030187.001545

Hatt, J.-M., \& Clauss, M. (2006). Feeding Asian and African elephants Elephas maximus and Loxodonta africana in captivity. International Zoo Yearbook, 40(1), 88-95. doi:10.1111/j.1748-1090.2006.00088.x

Hedges, S., \& Gunaryadi, D. (2010). Reducing humanelephant conflict: Do chillies help deter elephants from entering crop fields? Oryx, 44(1), 139-146. doi:10.1017/S0030605309990093

Heffner, H., \& Heffner, R. (1981). Functional interaural distance and high-frequency hearing in the elephant. The Journal of the Acoustical Society of America, 70(6), 1794-1795. doi:10.1121/1.387204 
Heffner, R. S., \& Heffner, H. E. (1982). Hearing in the elephant (Elephas maximus): Absolute sensitivity, frequency discrimination, and sound localization. Journal of Comparative and Physiological Psychology, 96, 926-944. doi:10.1037/0735-7036.96.6.926

Heffner, R. S., Heffner, H. E., \& Stichman, N. (1981). Role of the elephant pinna in sound localization. Animal Behaviour, 30, 628-629. doi:10.1016/S0003-3472(82)80078-X

Hollister-Smith, J. A., Alberts, S. C., \& Rasmussen, L. E. L. (2008). Do male African elephants, Loxodonta africana, signal musth via urine dribbling? Animal Behaviour, 76(6), 1829-1841. doi:10.1016/j.anbehav.2008.05.033

Irie, N., \& Hasegawa, T. (2012). Summation by Asian elephants (Elephas maximus). Behavioral Sciences, 2(2), 50-56. doi:10.3390/bs2020050

Irie, N., Hiraiwa-Hasegawa, M., \& Kutsukake, N. (2018). Unique numerical competence of Asian elephants on the relative numerosity judgment task. Journal of Ethology, 37, 111-115. doi:10.1007/s10164-018-0563-y

Irie-Sugimoto, N., Kobayashi, T., Sato, T., \& Hasegawa, T. (2008). Evidence of means-end behavior in Asian elephants (Elephas maximus). Animal Cognition, 11(2), 359-365. doi:10.1007/s10071-007-0126-Z

Irie-Sugimoto, N., Kobayashi, T., Sato, T., \& Hasegawa, T. (2009). Relative quantity judgment by Asian elephants (Elephas maximus). Animal Cognition, 12(1), 193-199. doi:10.1007/s10071-008-0185-9

Kahl, M. P., \& Armstrong, B. D. (2000). Visual and tactile displays in African elephants, Loxodonta africana: A progress report (1991-1997). Elephant, 2(4), 19-21. doi:10.22237/elephant/1521732201

Ketchaisri, O., Siripunkaw, C., \& Plotnik, J. M. (2019). The use of a human's location and social cues by Asian elephants in an objectchoice task. Animal Cognition, 22, 907-915. doi:10.1007/s10071-019-01283-0
King, L. E., Douglas-Hamilton, I., \& Vollrath, F. (2007). African elephants run from the sound of disturbed bees. Current Biology, 17(19), R832R833. doi:10.1016/j.cub.2007.07.038

King, L., Pardo, M., Weerathunga, S., Kumara, T. V., Jayasena, N., Soltis, J., \& de Silva, S. (2018). Wild Sri Lankan elephants retreat from the sound of disturbed Asian honey bees. Current Biology, 28(2), R64-R65. doi:10.1016/j.cub.2017.12.018

Langbauer, W. R. (2000). Elephant communication. Zoo Biology, 19(5), 425-445. doi:10.1002/1098 -2361(2000)19:5<425::AID-ZOO11>3.0.CO;2-A

Lazar, J., Greenwood, D. R., Rasmussen, L. E. L., \& Prestwich, G. D. (2002). Molecular and functional characterization of an odorant binding protein of the Asian elephant, Elephas maximus: Implications for the role of lipocalins in mammalian olfaction. Biochemistry, 41(39), 11786-11794. doi:10.1021/bi0256734

Lee, P. C., \& Moss, C. J. (1986). Early maternal investment in male and female African elephant calves. Behavioral Ecology and Sociobiology, 18(5), 353-361. Retrieved from JSTOR. doi:10.1007/BF00299666

Loveridge, A. J., Hunt, J. E., Murindagomo, F., \& Macdonald, D. W. (2006). Influence of drought on predation of elephant (Loxodonta africana) calves by lions (Panthera leo) in an African wooded savannah. Journal of Zoology, 270(3), 523-530. doi:10.1111/j.1469-7998.2006.00181.x

Makecha, R., Fad, O., \& Kuczaj II, S. A. (2012). The role of touch in the social interactions of Asian elephants (Elephas maximus). International Journal of Comparative Psychology, 25(1), 60-82.

Marino, L., Reiss, D., \& Gallup, G. G., Jr. (1994). Mirror self-recognition in bottlenose dolphins: Implications for comparative investigations of highly dissimilar species. In S. T. Parker, R. W. Mitchell, \& M. L. Boccia (Eds.), Selfawareness in animals and humans: Developmental perspectives (pp. 380-391). Cambridge, England: Cambridge University Press. doi:10.1017/CBO9780511565526.027 
Markowitz, H., Schmidt, M., Nadal, L., \& Squier, L. (1975). Do elephants ever forget? Journal of Applied Behavior Analysis, 8(3), 333-335. doi:10.1901/jaba.1975.8-333

Martin, R. B. (1978). Aspects of elephant social organization. Rhodesia Science News, 12, 184-187.

Maseko, B. C., Patzke, N., Fuxe, K., \& Manger, P. R. (2013). Architectural organization of the African elephant diencephalon and brainstem. Brain, Behavior and Evolution, 82(2), 83-128. doi:10.1159/000352004

McArthur, C., Finnerty, P. B., Schmitt, M. H., Shuttleworth, A., \& Shrader, A. M. (2019). Plant volatiles are a salient cue for foraging mammals: Elephants target preferred plants despite background plant odour. Animal Behaviour, 155, 199-216. doi:10.1016/j.anbehav.2019.07.002

McComb, K., Moss, C., Sayialel, S., \& Baker, L. (2000). Unusually extensive networks of vocal recognition in African elephants. Animal Behavior, 59(6), 1103-1109. doi:10.1006/anbe.2000.1406

McComb, K., Reby, D., Baker, L., Moss, C., \& Sayialel, S. (2003). Long-distance communication of acoustic cues to social identity in African elephants. Animal Behaviour, 65(2), 317-329. doi:10.1006/anbe.2003.2047

McComb, K., Shannon, G., Sayialel, K. N., \& Moss, C. (2014). Elephants can determine ethnicity, gender, and age from acoustic cues in human voices. Proceedings of the National Academy of Sciences, 111(14), 5433-5438. doi:10.1073/pnas.1321543111

McKay, G. M. (1973). The ecology and behavior of the Asiatic elephant in southeastern Ceylon. Smithsonian Contributions to Zoolology, 125, 1-113. doi:10.5479/si.00810282.125

Mikota, S. K. (2006). Integument System. in M. E. Fowler \& S. K. Mikota (Eds.), Biology, medicine, and surgery of elephants (pp. 253-262). Oxford, England: Blackwell Publishing Ltd.
Miller, A. K., Hensman, M. C., Hensman, S., Schultz, K., Reid, P., Shore, M., ... Lee, S. (2015). African elephants (Loxodonta africana) can detect TNT using olfaction: Implications for biosensor application. Applied Animal Behaviour Science, 171, 177-183. doi:10.1016/j.applanim.2015.08.003

Mizuno, K., Sharma, N., Idani, G. I., \& Sukumar, R. (2017). Collective behaviour of wild Asian elephants in risky situations: How do social groups cross roads? Behaviour, 154(12), 1215-1237. doi:10.1163/1568539X-00003465

Moss, C. J. (1983). Oestrous behaviour and female choice in the African elephant. Behaviour, 86(3/4), 167-196. doi:10.1163/156853983X00354

Moss, C. J. (1988). Elephant memories: Thirteen years in the life of an elephant family. Chicago, IL: University of Chicago Press.

Moss, C. J., Croze, H., \& Lee, P. C. (2011). The Amboseli elephants: A long-term perspective on a long-lived mammal. Chicago, IL: University of Chicago Press. doi:10.7208/chicago/9780226542263.001.0001

Mumby, H. S., \& Plotnik, J. M. (2018). Taking the elephants' perspective: Remembering elephant behavior, cognition and ecology in human-elephant conflict mitigation. Frontiers in Ecology and Evolution, 6, Article 122. doi:10.3389/fevo.2018.00122

Niimura, Y., Matsui, A., \& Touhara, K. (2014). Extreme expansion of the olfactory receptor gene repertoire in African elephants and evolutionary dynamics of orthologous gene groups in 13 placental mammals. Genome Research, 24(9), 14851496. doi:10.1101/gr.169532.113

Nissani, M. (2004). Elephant cognition: A review of recent experiments. Gajah, 28, 44-52.

Nissani, M. (2006). Do Asian elephants (Elephas maximus) apply causal reasoning to tool-use tasks? Journal of Experimental Psychology: Animal Behavior Processes, 32(1), 91-96. doi:10.1037/0097-7403.32.1.91 
Nissani, M., Hoefler-Nissani, D., Lay, U. T., \& Htun, U. W. (2005). Simultaneous visual discrimination in Asian elephants. Journal of the Experimental Analysis of Behavior, 83(1), 15-29. doi:10.1901/jeab.2005.34-04

O’Connell-Rodwell, C. E. (2007). Keeping an "ear" to the ground: Seismic communication in elephants. Physiology, 22(4), 287-294. doi:10.1152/physiol.00008.2007

O’Connell-Rodwell, C. E., Wood, J. D., Kinzley, C., Rodwell, T. C., Poole, J. H., \& Puria, S. (2007). Wild African elephants (Loxodonta africana) discriminate between familiar and unfamiliar conspecific seismic alarm calls. The Journal of the Acoustical Society of America, 122(2), 823-830. doi:10.1121/1.2747161

O’Connell-Rodwell, C. E., Wood, J. D., Rodwell, T. C., Puria, S., Partan, S. R., Keefe, R., ... Hart, L. A. (2006). Wild elephant (Loxodonta africana) breeding herds respond to artificially transmitted seismic stimuli. Behavioral Ecology and Sociobiology, 59(6), 842-850. doi:10.1007/s00265-005-0136-2

Payne, K. B., Langbauer, W. R., \& Thomas, E. M. (1986). Infrasonic calls of the Asian elephant (Elephas maximus). Behavioral Ecology and Sociobiology, 18(4), 297-301. doi:10.1007/BF00300007

Plotnik, J. M., Brubaker, D. L., Dale, R., Tiller, L. N., Mumby, H. S., \& Clayton, N. S. (2019). Elephants have a nose for quantity. Proceedings of the National Academy of Sciences, 116(25), 12566-12571. doi:10.1073/pnas.1818284116

Plotnik, J. M., \& de Waal, F. B. M. (2014). Asian elephants (Elephas maximus) reassure others in distress. PeerJ, 2, e278. doi:10.7717/peerj.278

Plotnik, J. M., de Waal, F. B. M., \& Reiss, D. (2006). Self-recognition in an Asian elephant. Proceedings of the National Academy of Sciences of the United States of America, 103(45), 17053-17057. doi:10.1073/pnas.0608062103
Plotnik, J. M., Pokorny, J. J., Keratimanochaya, T., Webb, C., Beronja, H. F., Hennessy, A., ... Getz, D. (2013). Visual cues given by humans are not sufficient for Asian elephants (Elephas maximus) to find hidden food. PLOS One, 8(4), e61174. doi:10.1371/journal.pone.0061174

Plotnik, J. M., Shaw, R. C., Brubaker, D. L., Tiller, L. N., \& Clayton, N. S. (2014). Thinking with their trunks: Elephants use smell but not sound to locate food and exclude nonrewarding alternatives. Animal Behaviour, 88, 91-98. doi:10.1016/j.anbehav.2013.11.011

Polla, E. J., Grueter, C. C., \& Smith, C. L. (2018). Asian elephants (Elephas maximus) discriminate between familiar and unfamiliar human visual and olfactory cues. Animal Behavior and Cognition, 5(3), 279-291. doi:10.26451/abc.05.03.03.2018

Poole, J. H. (1987). Rutting behavior in African elephants: The phenomenon of musth. Behaviour, 102(3/4), 283-316. doi:10.1163/156853986X00171

Poole, J. H. (1999). Signals and assessment in African elephants: Evidence from playback experiments. Animal Behaviour, 58(1), 185-193. doi:10.1006/anbe.1999.1117

Poole, J. H., \& Granli, P. K. (2009). Elephant voices elephant gestures database. Available from https://www.elephantvoices.org.

Poole, J. H., Payne, K., Langbauer, W. R., \& Moss, C. J. (1988). The social contexts of some very low frequency calls of African elephants. Behavioral Ecology and Sociobiology, 22(6), 385-392. doi:10.1007/BF00294975

Povinelli, D. J. (1989). Failure to find self-recognition in Asian elephants (Elephas maximus) in contrast to their use of mirror cues to discover hidden food. Journal of Comparative Psychology, 103(2), 122-131. doi:10.1037/0735-7036.103.2.122

Prior, H., Schwarz, A., \& Güntürkün, O. (2008). Mirror-induced behavior in the magpie (Pica pica): Evidence of self-recognition. PLOS Biology, 6(8), e202. doi:10.1371/journal.pbio.0060202 
Rasmussen, L. E. L. (2006). Chemical, tactile, and taste sensory systems. In M. E. Fowler \& S. K. Mikota (Eds.), Biology, medicine, and surgery of elephants (pp. 409-414). Ames, IA: Blackwell. doi:10.1002/9780470344484.ch32

Rasmussen, L. E. L., Lazar, J., \& Greenwood, D. R. (2003). Olfactory adventures of elephantine pheromones. Biochemical Society Transactions, 31(Pt. 1), 137-141. doi:10.1042/bst0310137

Rasmussen, L. E. L., \& Munger, B. L. (1996). The sensorineural specializations of the trunk tip (finger) of the Asian elephant, Elephas maximus. The Anatomical Record, 246(1), 127-134. doi:10.1002/(SICI)1097-0185(199609)246:1<127 ::AID-AR14>3.0.CO;2-R

Rasmussen, L. E. L., Riddle, H. S., \& Krishnamurthy, V. (2002). Mellifluous matures to malodorous in musth. Nature, 415(6875), 975-976. doi:10.1038/415975a

Rasmussen, L. E. L., \& Schulte, B. A. (1998). Chemical signals in the reproduction of Asian (Elephas maximus) and African (Loxodonta africana) elephants. Animal Reproduction Science, 53(1-4), 19-34. doi:10.1016/S0378-4320(98)00124-9

Rasmussen, L. E. L., \& Wittemyer, G. (2002). Chemosignalling of musth by individual wild African elephants (Loxodonta africana): Implications for conservation and management. Proceedings of the Royal Society B: Biological Sciences, 269(1493), 853-860. doi:10.1098/rspb.2001.1933

Rensch, B. (1957). The intelligence of elephants. Scientific American, 196(2), 44-49. doi:10.1038/scientificamerican0257-44

Rizvanovic, A., Amundin, M., \& Laska, M. (2013). Olfactory discrimination ability of Asian elephants (Elephas maximus) for structurally related odorants. Chemical Senses, 38(2), 107-118. doi:10.1093/chemse/bjs097
Rogaev, E. I., Moliaka, Y. K., Malyarchuk, B. A., Kondrashov, F. A., Derenko, M. V., Chumakov, I., \& Grigorenko, A. P. (2006). Complete mitochondrial genome and phylogeny of pleistocene mammoth Mammuthus primigenius. PLOS Biology, 4(3), e73. doi:10.1371/journal.pbio.0040073

Rohland, N., Reich, D., Mallick, S., Meyer, M., Green, R. E., Georgiadis, N. J., ... Hofreiter, M. (2010). Genomic DNA sequences from mastodon and woolly mammoth reveal deep speciation of forest and savanna elephants. PLOS Biology, 8(12), e1000564. doi:10.1371/journal.pbio.1000564

Ruggiero, R. G. (1991). Opportunistic predation on elephant calves. African Journal of Ecology, 29, 86-89. doi:10.1111/j.1365-2028.1991.tb00823.x

Ruzicka, R. E., \& Conover, M. R. (2012). Does weather or site characteristics influence the ability of scavengers to locate food? Ethology, 118(2), 187-196. doi:10.1111/j.1439-0310.2011.01997.x

Sampson, C., McEvoy, J., Oo, Z. M., Chit, A. M., Chan, A. N., Tonkyn, D., ... Leimgruber, P. (2018). New elephant crisis in Asia-Early warning signs from Myanmar. PLOS One, 13(3), e0194113. doi:10.1371/journal.pone.0194113

Savage, A., Rice, J. M., Brangan, J. M., Martini, D. P., Pugh, J. A., \& Miller, C. D. (1994). Performance of African elephants (Loxodonta africana) and California sea lions (Zalophus californianus) on a two-choice object discrimination task. Zoo Biology, 13(1), 69-75. doi:10.1002/zoo.1430130109

Schmitt, M. H., Shuttleworth, A., Ward, D., \& Shrader, A. M. (2018). African elephants use plant odours to make foraging decisions across multiple spatial scales. Animal Behaviour, 141, 17-27. doi:10.1016/j.anbehav.2018.04.016

Short, J. (1981). Diet and feeding behaviour of the forest elephant. Mammalia, 45(2), 177-186. doi:10.1515/mamm.1981.45.2.177 
Shoshani, J., Kupsky, W. J., \& Marchant, G. H. (2006). Elephant brain: Part I: Gross morphology, functions, comparative anatomy, and evolution. Brain Research Bulletin, 70(2), 124-157. doi:10.1016/j.brainresbull.2006.03.016

Shyan-Norwalt, M. R., Peterson, J., King, B. M., Staggs, T. E., \& Dale, R. H. I. (2010). Initial findings on visual acuity thresholds in an African elephant (Loxodonta africana). Zoo Biology, 29(1), 30-35. doi:10.1002/zoo.20259

Smet, A. F., \& Byrne, R. W. (2013). African elephants can use human pointing cues to find hidden food. Current Biology, 23(20), 2033-2037. doi:10.1016/j.cub.2013.08.037

Soltis, J., Leong, K., \& Savage, A. (2005a). African elephant vocal communication I: Antiphonal calling behaviour among affiliated females. Animal Behaviour, 70(3), 579-587. doi:10.1016/j.anbehav.2004.11.015

Soltis, J., Leong, K., \& Savage, A. (2005b). African elephant vocal communication II: Rumble variation reflects the individual identity and emotional state of callers. Animal Behaviour, 70(3), 589-599. doi:10.1016/j.anbehav.2004.11.016

Stoeger, A. S., \& Baotic, A. (2017). Male African elephants discriminate and prefer vocalizations of unfamiliar females. Scientific Reports, 7, Article 46414. doi:10.1038/srep46414

Stoeger, A. S., Mietchen, D., Oh, S., de Silva, S., Herbst, C. T., Kwon, S., \& Fitch, W. T. (2012). An Asian elephant imitates human speech. Current Biology, 22(22), 2144-2148. doi:10.1016/j.cub.2012.09.022

Stone, J., \& Halasz, P. (1989). Topography of the retina in the elephant Loxodonta africana. Brain, Behavior and Evolution, 34, 84-95. doi:10.1159/000116494

Talsma, D., Senkowski, D., Soto-Faraco, S., \& Woldorff, M. G. (2010). The multifaceted interplay between attention and multisensory integration. Trends in Cognitive Sciences, 14(9), 400-410. doi:10.1016/j.tics.2010.06.008
Thompson, M. E., Schwager, S. J., \& Payne, K. B. (2010). Heard but not seen: An acoustic survey of the African forest elephant population at Kakum Conservation Area, Ghana. African Journal of Ecology, 48(1), 224-231. doi:10.1111/j.1365-2028.2009.01106.x

Thuppil, V., \& Coss, R. G. (2013). Wild Asian elephants distinguish aggressive tiger and leopard growls according to perceived danger. Biology Letters, 9(5), 20130518. doi:10.1098/rsbl.2013.0518

Vidya, T. N. C., \& Sukumar, R. (2005). Social and reproductive behaviour in elephants. Current Science, 89(7), 1200-1207.

von Békésy, G., \& Wever, E. G. (1960). Experiments in hearing (Vol. 8). New York, NY: McGraw-Hill.

von Dürckheim, K. E. M., Hoffman, L. C., Leslie, A., Hensman, M. C., Hensman, S., Schultz, K., \& Lee, S. (2018). African elephants (Loxodonta africana) display remarkable olfactory acuity in human scent matching to sample performance. Applied Animal Behaviour Science, 200, 123-129. doi:10.1016/j.applanim.2017.12.004

Wijayagunawardane, M. P., Short, R. V., Samarakone, T. S., Nishany, K. M., Harrington, H., Perera, B. V. P., ... Bittner, E. P. (2016). The use of audio playback to deter crop-raiding Asian elephants. Wildlife Society Bulletin, 40(2), 375-379. doi:10.1002/wsb. 652

Wittemyer, G., Douglas-Hamilton, I., \& Getz, W. M. (2005). The socioecology of elephants: Analysis of the processes creating multitiered social structures. Animal Behaviour, 69(6), 1357-1371. doi:10.1016/j.anbehav.2004.08.018

Wittemyer, G., Northrup, J. M., Blanc, J., DouglasHamilton, I., Omondi, P., \& Burnham, K. P. (2014). Illegal killing for ivory drives global decline in African elephants. Proceedings of the National Academy of Sciences, 111(36), 13117-13121. doi:10.1073/pnas.1403984111 
Yasui, S., \& Idani, G. I. (2017). Social significance of trunk use in captive Asian elephants. Ethology Ecology \& Evolution, 29(4), 330-350. doi:10.1080/03949370.2016.1179684

Yokoyama, S., Takenaka, N., Agnew, D. W., \& Shoshani, J. (2005). Elephants and human color-blind deuteranopes have identical sets of visual pigments. Genetics, 170(1), 335-344. doi:10.1534/genetics. 104.039511 